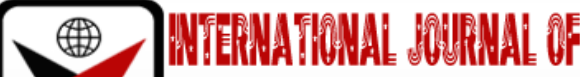

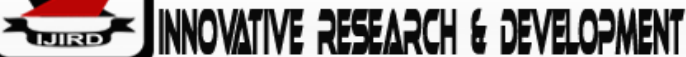

ISSN 2278-0211 (Online)

\section{Promoting Rural Development through Development of Alternative Technology for High Quality Cassava Flour Production}

Ishola, T.A
Principal Lecturer, Department of Agricultural Education,
Michael Otedola College of Primary Education, Lagos, Nigeria
Y.A Salako
Lecturer, Department of Agricultural Education,
Otedola College of Primary Education, Noforija, Epe, Lagos, Nigeria
K.0. Abdul
Lecturer, Department of Agricultural Education,
Michael Otedola College of Primary Education, Lagos, Nigeria
L.o Odulate
Lecturer, Department of Agricultural Education,
Michael Otedola College of Primary Education, Lagos, Nigeria
I.o Olaoye
Senior Lecturer, Department of Agricultural Engineering,
Technical University, Oyo State, Nigeria

\begin{abstract}
:
An alternative technology for timely drying of cassava mash for the production of High-Quality Cassava Flour (HQCF) was examined in this study. A motorized gari fryer primarily developed for gari production was improvised for drying the mash. The effect of different temperature levels of the machine (viz: 45, 50, 55, 60, and $65^{\circ} \mathrm{C}$ ) below the gelatinization temperature on some of the physicochemical properties of the product were examined. The machine temperature level above $60^{\circ} \mathrm{C}$ affect the quality of the cassava mash due to gelatinization of some of the flour particle and slight change in colour of the flour produced. Temperatures below this optimum level prolong the drying rate of the mash and also affect the overall production target. This drying method significantly reduces the moisture content to a standard level within 30 minutes of drying which consequently promotes the $\mathrm{pH}$ value and colour of the flour produced. The study concludes that timely drying of cassava flour to achieve high standard quality flour is achievable at local level of production. The existing gari processing center within the study area can be utilized for this production of HQCF provided the fryer is adjusted to optimum temperature and the procedure recommended in this study is strictly followed. The effect of the drying methods considered on the physicochemical properties of the flour was determined at $p<0.05$ significance level.
\end{abstract}

Keywords: Moisture migration, physicochemical, alternative technology, gelatinization, temperarture levels

\section{Introduction}

High Quality Cassava Flour (HQCF) is an intermediate product mostly used as an alternative for starch and other imported materials such as wheat flour in a variety of industries. This unfermented cassava flour can be used as partial replacement for wheat flour in bakery and pasta products without any change to the taste or other qualities (Njoku, Amadi, Mbe and Amanze, 2014). The substitution ratio varies, depending on the product and the quality of the cassava flour. Cassava flour has also found wide application in pharmaceutical industries for the production of glucose syrup and as an extender for plywood glues in paper industries. It is also used as a source of starch in textile industries and in the production of industrial and portable alcohol.

The basic steps involved in the processing of cassava roots into HQCF involves peeling, washing, grating, pressing, disintegration, sifting, drying, milling, screening, packaging and storage. Slicing/chipping can also serve as an alternative to grating, pressing, disintegration and sifting. However, slicing / chipping has been found unsuitable for bitter varieties because the concentration of cyanogenic glucosides was not reduced sufficiently during processing. Having selected a matured high-quality cassava root, all the processes involved in the production of the cassava flour must be achieved within one day of harvest in order to attain standard quality cassava flour. Predominantly, cassava farmers in the study 
area prefer processing of their cassava into gaari, due to relatively ease of production and less sensitive in terms of timeliness of production.

Cottage and local production of HQCF has been a mirage due to fragmented cultivation of cassava less than 2 ha in scattered plots, lack of appropriate technology necessary for its production among the peasant cassava farmers who occupy a major position in the industry (Onyenwoke and Simonyan, 2014).

Also, production of HQCF requires conscious adherence to standard practice in order to obtain a product of desirable quality that can be utilized as an intermediate product in industries or as partial replacement for many bakery and pasta products (Iwe et al., 2017). Production of quality cassava flour at this level of production will remain obscure if challenges as a result of large numbers of smallholder farmers in scattered plots, lack of production capacity, inappropriate intermediate technology among other factors are not urgently addressed. This is because the emerging markets for HQCF make orders and expect deliveries in large quantities in systems that are not currently set up to accommodate a large number of variable quality suppliers.

These quality specifications for cassava flour make the production of cassava flour more technically challenging than gari production. The process line must therefore be such that all the necessary processing conditions which affect quality are well taken care of. These processing conditions or treatments will be enumerated in the description of the production process. High quality cassava flour (HQCF) should be white and have no odor, it should not be contaminated by insects or microorganisms and it is best to use cassava cultivars which contain low level of cyanogenic compounds (Lin, Li, $\mathrm{Xu}$, Jian, \& Zhang, 2016). However, the hydrocyanic content of fresh cassava roots is not a serious problem in cassava flour production, since it is almost entirely eliminated during processing.

Some of the challenges that also scare smallholder of cassava farm from embarking on the production of HQCF is the ability to process and dry the flour to a safe moisture level within 24 hours after harvesting. Fluctuation in weather condition for appropriate drying in the case of sunlight, lack of affordable drying equipment and unstable source of power to power the artificial dryer are the major challenges that discourage the local production.

In line with the foregoing, there is therefore the need to embark on a study to address the challenge of timely drying of cassava flour to achieve a standard quality. It is against this background that this study seeks to examine an alternative technology that can easily be adopted by the local/rural and cottage processor of cassava in their operations to maximize the potentials of small cassava farm holders in the study area. This will undoubtedly improve their standard of living particularly in the present economic situation as a result of the pandemic crisis by competing favorably in the production of HQCF thereby improving their lives towards a sustainable rural development strategy.

\section{Materials and Methods}

\subsection{Site Location and Equipment}

An integrated cassava processing center was strategically located to encourage small cassava farm holders in the production of High-Quality Cassava Flour (HQCF). Basic equipment such as motorized gari fryer, hydraulic press, hammer mill, disc-attrition mill and so on were developed through the intervention of Tertiary Education Trust Fund (TETFund). Pilot experiment was carried out to demonstrate to the farmers on the innovative techniques for achieving quality cassava flour production. The details of the experimental work carried out to determine the optimum temperature level for effective drying without gelatinization of the samples, determination of the moisture content at interval at various drying temperature, and other processing stages procedure were presented here.

\subsection{Methodology}

Cassava was processed following the procedure as indicated in Figure 1. The major focus of this work is the timely drying of the sample for achieving standard quality flour. The cassava mash was dried at different temperature levels (viz: $50,55,60,65$ and $70^{\circ} \mathrm{C}$ ) using motorized gari fryer to determine the optimum temperature for the timely drying of the samples without gelatinization and also preserve the flour quality. Some of the properties of the flour produced such as moisture content, $\mathrm{pH}$ value, colour, ash content, water absorption capacity etc. were determined for qualitative analysis of the flour produced.

\subsection{Sample Preparation}

Freshly harvested, good quality and matured cassava roots (10 to 12 months old) were selected for processing. Low moisture cassava varieties were selected because of its high recovery rate and better starch quality. The tubers were washed to remove soil and dirt that accompanies the freshly uprooted cassava tubers into the processing plant. The tubers after washing were peeled manually with knife so that the final product is free of fragments. To completely remove all forms of dirt that can affect the quality of the final product, the tubers were washed again after peeling. The peeled tubers were then soaked in fresh water for short period (one hour) to avoid discoloration and ensure whiteness until grating into a wet mash. Since fermentation is not required for HQCF production, the mash was pressed immediately under high pressure using hydraulic press to about 35\% to $40 \%$ moisture content. The lower moisture content allows the cassava meal to dry quickly during drying. After pressing, the cassava cakes were pulverized and sifted to remove most of its fiber content. The sifted meal is dried at various temperature levels to determine the optimum temperature below its gelatinization temperature for fast drying. The dried product was milled and sifted using a $0.25 \mathrm{~mm}$ metal mesh to produce a finely milled product containing minimum fiber levels. A control experiment using sun drying on a raised platform was also conducted to determine the effect of the improvised dryer on the final product. The quality of the final products such as colour, moisture content, $\mathrm{pH}$, and particle size at the different processing conditions were determined. 


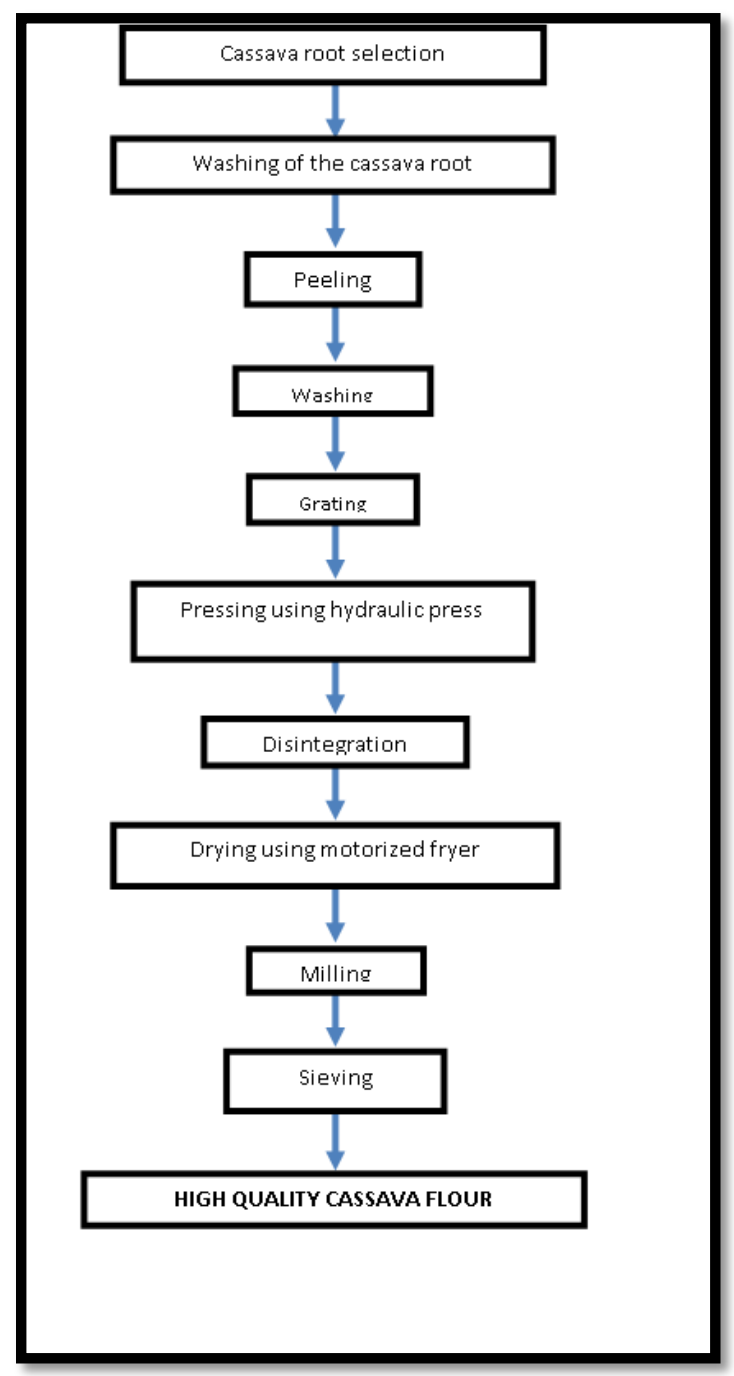

Figure 1: Flow Chart of the HQCF Production

\subsection{Determination of the Physicochemical Properties of the Cassava Flour}

\subsubsection{Determination of the Moisture Content}

The moisture content was determined using the standard method prescribed in ASTM D2016-25 (Salako, Awolarafe and Anozie, 2009) by drying about $2 \mathrm{~g}$ of the fuel sample in an oven at $105^{\circ} \mathrm{C}$ for about 1 hour 30 minutes. The dried sample was placed in a dessicator for $30 \mathrm{~min}$ to cool before weighing the moisture content wet basis was calculated as given by the equation:

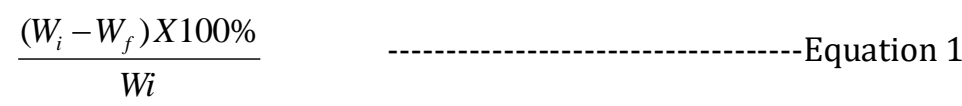

where:

$\mathrm{W}_{\mathrm{i}} \quad=\quad$ initial weight of the material (before drying)

$\mathrm{W}_{\mathrm{f}} \quad=\quad$ weight of the material after drying

\subsubsection{Colour and Odour}

The odour and colour difference in the cassava flour samples was determined using physical examination. This is done following the procedure described by Aurelie and Louise (2012).

\subsection{3. $\mathrm{pH}$}

A measure of $10.0 \mathrm{~g}$ of flour sample was weighed into a $250 \mathrm{ml}$ beaker, and then $90 \mathrm{ml}$ of distilled water was added and mixed well. The mixture was left for 1 hour at room temperature. The $\mathrm{pH}$ was measured in triplicate using a $\mathrm{pH}$ meter.

\subsubsection{Ash Content}

Ash content of a material is the residue after the material has been burnt, and serves as the parameter used to determine the burning rate of the biomass materials. The ash content was determined by following the procedure of ASTM D-5142 as reported by Salako et al. (2011). About $2 \mathrm{~g}$ of the samples were burnt in muffled furnace at $800^{\circ} \mathrm{C}$ for 5 hours and allowed to cool down in a desiccator. The ash content was calculated using the equation below. 
$\%$ Ash content $=\left(\frac{\text { final weight } * 100}{\text { initial weight }}\right)$

Equation 2

\subsection{Water Absorption Capacity}

Water absorption capacity was determined using the method described by Hasmadi, Harlina, Jau- Shya, Mansoor, Jahurul, and Zainol, 2020). A measure of $2 g$ of cassava flour was poured into a centrifuge of a known weight. Distilled water $(40 \mathrm{ml})$ was then added to the centrifuge containing the flour. The solution was held for 30 minutes and stirred occasionally during this period after which centrifugation was carried out for 15 minutes. The liquid lying above the solid residue after centrifugation was decanted. Excess moisture removed by draining for $24 \mathrm{hrs}$. at $50^{\circ} \mathrm{C}$ and the sample was reweighed. The amount of water bound by the flour was determined by difference and expressed as weight of water bound by dry flour (100g).

\section{Results and Discussion}

The moisture migration of the samples is as presented in tables 1 and 2 . The initial moisture content of the samples after pressing and disintegration was 38\% for all the samples. The standard moisture content of the flour was attained after 4 days of drying with an average daily ambient temperature and relative humidity of $31{ }^{\circ} \mathrm{C}$ and $81 \%$ respectively. The artificial drying using the motorized fryer at adjusted temperature levels reached a safe moisture level for flour within 30 minutes of drying. The moisture content was measured from the samples every 5 minutes of drying and the results indicated that a promising temperature range for fast drying of the sample ranges between 55 to $65^{\circ} \mathrm{C}$. Lower temperature levels will also achieve the desired result but at a longer drying time. Moisture content showed significant difference ( $p>0.05)$ between the two modes of drying. This finding is in line with the findings of Oginni et al (2015).

The colour of the flour produced was examined physically. The control experiment showed a slight change in the whiteness of the flour colour. Samples 1 to 4 exhibited a purely white colour while sample 5 as shown in the table exhibited a slightly creamy colour. This indicated that the prolonged drying time using sun drying has a major effect of colour quality of the flour which is a major factor for selecting a standard HQCF. The samples using the alternative technology at temperature ranging between 45 and $60^{\circ} \mathrm{C}$ produced a high quality in terms of colour which is as a result of the timely drying of the mash. Temperature above $60^{\circ} \mathrm{C}$ is not suitable for cassava flour production because of the slight change in colour noticed. This indicated that gelatinization has started taking place in some of the particles which will equally affect the flour quality. This result is in line with the findings of Oyedeji, Sobukola, Henshaw, Adegunwa, Ijabadeniyi, Sanni, and Tomlins, 2015.

The $\mathrm{pH}$ value obtained for sun drying sample was higher than the alternative drying method. An average value of $4.87 \%$ was obtained for sun drying while $7.09 \%$ was obtained using the alternative drying technology. The standard $\mathrm{pH}$ value for quality cassava must not exceed 5.5\% as stated by Aurelie and Louise (2012). The sample prepared by sun drying has started fermenting due to the time lag between the cassava harvesting and the final product. The alternative drying was essential for the timeliness of the operation which is evident in the $\mathrm{pH}$ value of $7.09 \%$ obtained.

The ash content and the water absorption capacity showed no significant difference ( $\mathrm{p}>0.05)$ at both drying methods. This indicated that the method of drying and the time lag for the drying process has no significant on the ash content and the water absorption capacity of the final product obtained. This result obtained is corroborated in the findings of Hasmadi et al 2020.

\begin{tabular}{|c|c|c|}
\hline Drying Days (8 hours Daily & Initial Moisture Content (\%) & Final Moisture Content (MC) (\%) \\
\hline Day 1 & $38 \pm 0.01$ & $29 \pm 0.02$ \\
\hline Day 2 & $28 \pm 0.03$ & $22 \pm 0.03$ \\
\hline Day 3 & $23 \pm 0.01$ & $13 \pm 0.01$ \\
\hline Day 4 & $13 \pm 0.04$ & $12 \pm 0.03$ \\
\hline
\end{tabular}

Table 1: Moisture Migration from Cassava Mash under Open Air Sun Drying Values Were in Triplicates and Expressed as Mean \pm S.D.

\begin{tabular}{|c|c|c|c|c|c|}
\hline \multirow{2}{*}{$\begin{array}{l}\text { Drying Time } \\
\text { (min) }\end{array}$} & Sample 1 & Sample 2 & Sample 3 & Sample 4 & Sample 5 \\
\hline & MC @45ㄷ Temp (\%) & $\begin{array}{c}\mathrm{MC} @ 50^{\circ} \mathrm{C} \\
\text { Temp }\end{array}$ & $\begin{array}{l}\text { MC @55C } \\
\text { Temp (\%) }\end{array}$ & $\begin{array}{l}\text { MC @60 } \\
\text { Temp (\%) }\end{array}$ & $\begin{array}{l}\mathrm{MC} @ 65^{\circ} \mathrm{C} \\
\text { Temp (\%) }\end{array}$ \\
\hline 0 & $38 \pm 0.01$ & $38 \pm 0.01$ & $38 \pm 0.01$ & $38 \pm 0.01$ & $38 \pm 0.01$ \\
\hline 5 & $35 \pm 0.03$ & $32 \pm 0.01$ & $30 \pm 0.03$ & $30 \pm 0.03$ & $28 \pm 0.02$ \\
\hline 10 & $27 \pm 0.02$ & $24 \pm 0.04$ & $22 \pm 0.02$ & $20 \pm 0.04$ & $17 \pm 0.02$ \\
\hline 15 & $22 \pm 0.01$ & $20 \pm 0.02$ & $19 \pm 0.01$ & $17 \pm 0.01$ & $13 \pm 0.01$ \\
\hline 20 & $19 \pm 0.04$ & $19 \pm 0.01$ & $16 \pm 0.04$ & $14 \pm 0.01$ & $12 \pm 0.04$ \\
\hline 25 & $17 \pm 0.01$ & $14 \pm 0.03$ & $13 \pm 0.01$ & $12 \pm 0.04$ & $10 \pm 0.02$ \\
\hline 30 & $16 \pm 0.03$ & $13 \pm 0.01$ & $11 \pm 0.01$ & $10 \pm 0.01$ & $9 \pm 0.03$ \\
\hline
\end{tabular}

Table 2: Moisture Migration from Cassava Mash at Different Levels of Drying Temperature

Values Were in Triplicates and Expressed As Mean \pm S.D. 


\begin{tabular}{|c|c|c|c|c|c|}
\hline Samples & Final MC (\%) & Colour & pH (\%) & Ash content (\%) & Water Absorption (mL/g) \\
\hline Control & $12 \pm 0.3$ & $\begin{array}{c}\text { Not pure } \\
\text { white }\end{array}$ & $4.87 \pm 0.13$ & $2.58 \pm 0.014$ & $1.63 \pm 0.01$ \\
\hline Sample 1 & $16 \pm 0.3$ & White & $7.09 \pm 0.45$ & $2.49 \pm 0.017$ & $1.63 \pm 0.06$ \\
\hline Sample 2 & $13 \pm 0.1$ & White & $7.09 \pm 0.17$ & $2.49 \pm 0.012$ & $1.63 \pm 0.04$ \\
\hline Sample 3 & $11 \pm 0.1$ & White & $7.09 \pm 0.23$ & $2.49 \pm 0.011$ & $1.63 \pm 0.01$ \\
\hline Sample 4 & $10 \pm 0.1$ & White & $7.09 \pm 0.19$ & $2.49 \pm 0.015$ & $1.63 \pm 0.07$ \\
\hline Sample 5 & $9 \pm 0.3$ & $\begin{array}{c}\text { Slightly } \\
\text { creamy }\end{array}$ & $7.09 \pm 0.14$ & $2.49 \pm 0.018$ & $1.63 \pm 0.09$ \\
\hline
\end{tabular}

Table 3: Physiochemical Properties of Cassava Flour at Different Level of Drying Temperature Values Were in Triplicates and Expressed As Mean \pm S.D.

\section{Conclusion}

Production of High-Quality Cassava Flour (HQCF) at local and cottage level is possible using the motorized gari fryer adjusted to a temperature below the gelatinization temperature. The complete processing from harvesting and the final product can be achieved within 3 hours which reduces the chances of fermentation and colour changes of the mash. This research work recommended an optimum temperature of $60^{\circ} \mathrm{C}$ for the motorized gari fryer for fast drying of the flour without being gelatinized. The alternative technology introduced in this study plays a major role in the moisture content, $\mathrm{pH}$ value and colour of the product. However, it has no significant effect on the ash content and water absorption capacity. Adoption of this alternative technology by the local and cottage processor of cassava for HQCF will open the opportunity of local and foreign earning in the production of the product and will consequently improve the standard of living of local rural farmers.

\section{Conflicts of Interest}

The authors declare that there are no conflicts of interest regarding the publication of this paper

\section{Acknowledgements}

The authors wish to thank the Tertiary Education Trust Fund (TetfFund) Nigera, for funding this work under the Industrial Based Research (IBR) scheme. The research team also wish to acknowledge the effort of the management of Michael Otedola College of Primary Education (MOCPED) Epe, Lagos, Nigeria for providing the structure for the cassava processing factory where the equipment developed were installed for the local production of HQCF.

\section{References}

i. Aurelie Bechoff and Louise Abayomi. (2012). Analyses of High-Quality Cassava Flour (HQCF) quality at Natural Research Institute in 2012. Natural Resource Institute. C:AVA

ii. Hasmadi, M., Harlina, L., Jau-Shya, L., Mansoor, A.H., Jahurul, M.H.A. and Zainol, M.K.

iii. (2020). Physicochemical and functional properties of cassava flour grown in different locations in Sabah, Malaysia. Food Research journal 4 (4): 991 - 999.

iv. Iwe, Madu Ofo, Michael N, Madu N, Nneoma Elechi Obasi: Physicochemical and Pasting Properties High Quality Cassava Flour (HQCF) and Wheat Flour Blends January 2017. http://Agrotechnology 06(03) /doi.org/10.4172/2168-9881.1000167.

v. Lin, L. M., Li, K. M., Xu, H., Jian, C. P., \& Zhang, Z. W. (2016). Analysis on processing of cassava flour and cassava powder. Journal of Tropical Biology 7(1), 58-63.on processing characteristics of cassava flour and c assava powder.

vi. Journal of Tropical Biology, 7(1), 58-63. (In Chinese.)

vii. Luna, C., \& Estévez, M. (2019). Formation of allysine inon processing characteristics of cassava flour and c assava powder.

viii. Journal of Tropical Biology, 7(1), 58-63. (In Chinese.)

ix. Luna, C., \& Estévez, M. (2019). Formation of allysine I on processing characteristics of cassava flour and cassava powder.

x. Journal of Tropical Biology, 7(1), 58-63. (In

xi. Njoku D.N., Amadi, C.O., Mbe J and Amanze N.J. (2014). Strategies to overcome post-harvest physiological deterioration in cassava (Manihot esculenta) root: A review Niger. Agric. Journal 45 51- 62.

xii. Oginni, O. C., O. P. Sobukola, F. O. Henshaw, W. A. O. Afolabi, and L. Munoz. (2015). 'Effect of starch gelatinization and vacuum frying conditions on structure development and associated quality attributes of cassava-gluten based snack' Food Structure Journal, Vol 3 Pp12-20 45 51- 62

xiii. Onyenwoke, C.A. and Simonyan K.J. (2014). Cassava post-harvest processing and storage in Nigeria: A review Africa Journal of Agricultural Research Vol.9 3853-63

xiv. Oyedeji, A. B., O. P. Sobukola, Folake Henshaw, M. O. Adegunwa, O. A. Ijabadeniyi, L. O. Sanni, and K. I. Tomlins. (2017). Effect of Frying Treatments on Texture and Colour Parameters of Deep Fat Fried Yellow Fleshed Cassava Chips. Journal of food Quality, Vol. 2017 Article ID8373801, 10 pages, 2017 http://doi.org/10.115/2017/8373801

XV. Salako, Y.A., Owolarafe, O. K. and Anozie, A. N. (2009). Characterization of sundried palm fruit waste biomass materials. Ife journal of technology. 18(2): $26-30$. 